Research Article

\title{
Compact Band-Selective Power Divider Using One-Dimensional Metamaterial Structure
}

\author{
Soonwoo Park $\mathbb{D},{ }^{1}$ Heeje Han $\mathbb{D}^{1},{ }^{1}$ Chanwoo Kim $\mathbb{D}^{1},{ }^{1}$ Jaemin Bae $\mathbb{D},{ }^{1}$ Youngki Cho, ${ }^{2}$ \\ and Hongjoon Kim iD ${ }^{1}$ \\ ${ }^{1}$ Department of Electrical Engineering, Kyungpook National University, 80, Daehak-ro, Buk-gu, Daegu 41566, Republic of Korea \\ ${ }^{2}$ School of Electronics Engineering Kyungpook National University, 80, Daehak-ro, Buk-gu, Daegu 41566, Republic of Korea \\ Correspondence should be addressed to Hongjoon Kim; hongjoon@knu.ac.kr
}

Received 5 September 2019; Accepted 20 November 2019; Published 6 December 2019

Academic Editor: Atsushi Mase

Copyright ( 12019 Soonwoo Park et al. This is an open access article distributed under the Creative Commons Attribution License, which permits unrestricted use, distribution, and reproduction in any medium, provided the original work is properly cited.

A band-selective power divider is demonstrated for the first time. By replacing lumped element right-handed (RH) and lefthanded (LH) transmission lines (TL) in a conventional Wilkinson power divider, it is possible to achieve both power division and filtering simultaneously. By utilizing the positive phase propagation property of an RHTL, which works as a low-pass filter, and the negative phase propagation property of an LHTL, which works as a high-pass filter, the band-selective quarter-wave sections required to construct a Wilkinson power divider are implemented. The fabricated circuit shows an insertion loss in the range $1.7 \mathrm{~dB}-2.5 \mathrm{~dB}$ in the passband, with the circuit dimensions of merely $12 \mathrm{~mm}$ by $10 \mathrm{~mm}$.

\section{Introduction}

Many radio-frequency and microwave systems require power dividing and combining processes. As a Wilkinson power divider [1] can match all the ports with the same characteristic impedance and isolate ports effectively, various types of such dividers have been introduced [2-6] to minimize the size $[3,4]$ and increase the bandwidth $[5,6]$. Recently, several dual-band Wilkinson dividers have been reported $[7,8]$ but they still require long microstrip transmission lines, making the size of the power divider large. Moreover, it is difficult to select the desired band in such structures. To overcome such limitations, a compact and broadband tunable Wilkinson power divider has been introduced in [9].

Furthermore, band-pass filtering is an essential process to filter out unwanted signals in many wireless systems. Particularly, in a modern multimode and multiband communication system, effective signal filtering is a very important issue. When it is required to split power and filter signals, a power dividing element and a band-pass filter must be cascaded. This may degrade the overall system performance in terms of loss, size, and efficiency. To improve these degradations, various research studies have been carried out to achieve both power dividing and filtering characteristics in a single circuit [10-12]. The author of reference [11] used a series connected band-pass filter and a low-pass filter to replace the quarter-wave section of the Wilkinson power divider, and the author of reference [12] suggested a power divider using a coupled microstrip line structure.

Recently, various applications of left-handed transmission lines (LHTLs) have been demonstrated for novel microwave circuits [13-15]. A synthetic transmission line composed of series capacitors and shunt inductors shows negative phase propagation [13-15]. It is evident that the structure itself is a high-pass filter. This structure is the dual of a right-handed transmission line (RHTL), where series inductors and shunt capacitors are periodically loaded. This conventional RHTL works as a low-pass filter.

Our main idea is to combine a synthetic RHTL and a synthetic LHTL to realize quarter-wave sections in a conventional Wilkinson power divider. With this method, it is possible to achieve effective power division and band-pass 
filtering simultaneously. Moreover, as this circuit is made with lumped elements only, it is compact in size especially when the circuit is designed for low-frequency band. Due to this advantage, proposed circuit is a good candidate for many compact and portable microwave systems.

\section{RHTL and LHTL Theory}

As there are many articles regarding the structures and analysis of RHTL and LHTL, we briefly review the theories to explain the operation of a band-selective power divider.

Figure 1(a) shows a section of an RHTL. The section is constructed with two series inductors and a shunt varactor. As this is a low-pass filter structure, the periodic cut-off frequency (Bragg cut-off frequency) is given by equation (1) when several identical sections are cascaded [11]:

$$
f_{\text {Bragg }}^{\mathrm{R}}=\frac{1}{\pi \cdot \sqrt{L_{\mathrm{R}} C_{\mathrm{R}}}} .
$$

Here, $L_{\mathrm{R}}$ is a series inductor and $C_{\mathrm{R}}$ is a shunt capacitor. In this synthetic transmission line, the characteristic impedance $\left(Z_{0 \mathrm{R}}\right)$ also can be approximated as follows:

$$
Z_{0 \mathrm{R}}=\sqrt{\frac{L_{\mathrm{R}}}{C_{\mathrm{R}}}} .
$$

The phase propagation constant $\left(\beta_{\mathrm{R}}\right)$ is given by the following equation [11]:

$$
\cos \left(\beta_{\mathrm{R}}\right)=1-(2 \pi f)^{2} \frac{L_{\mathrm{R}} C_{\mathrm{R}}}{2} .
$$

Figure 1(b) shows a section of an LHTL. The Bragg cut-off frequency, characteristic impedance $\left(Z_{0 \mathrm{~L}}\right)$, and phase propagation constant $\left(\beta_{\mathrm{L}}\right)[11]$ are, respectively, given as follows:

$$
\begin{aligned}
f_{\text {Bragg }}^{\mathrm{L}} & =\frac{1}{4 \pi \cdot \sqrt{L_{\mathrm{L}} C_{\mathrm{L}}}}, \\
Z_{0 \mathrm{~L}} & =\sqrt{\frac{L_{\mathrm{L}}}{C_{\mathrm{L}}}} \\
\sin \left(\beta_{\mathrm{L}} / 2\right) & =-\frac{1}{4 \pi f \sqrt{L_{\mathrm{L}} C_{\mathrm{L}}}} .
\end{aligned}
$$

The structure is high-pass filter with negative phase propagation, as shown in equation (6).

\section{Band-Selective Power Divider}

Figure 2 shows our main idea. We replaced $\lambda / 4$ sections of a conventional Wilkinson power divider by cascading several sections of an RHTL and an LHTL so that

$$
\begin{gathered}
\beta_{\text {TOTAL }}=m \beta_{\mathrm{R}}+n \beta_{\mathrm{L}}=\lambda / 4, \\
Z_{0 \mathrm{R}}=Z_{0 \mathrm{~L}}=\sqrt{2} Z_{0},
\end{gathered}
$$

where $m$ and $n$ represent the number of identical sections of the RHTL and LHTL, respectively. Note that $\beta_{\mathrm{L}}$ is negative in (7).

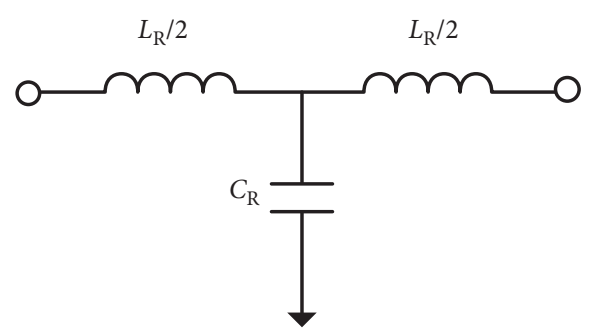

(a)

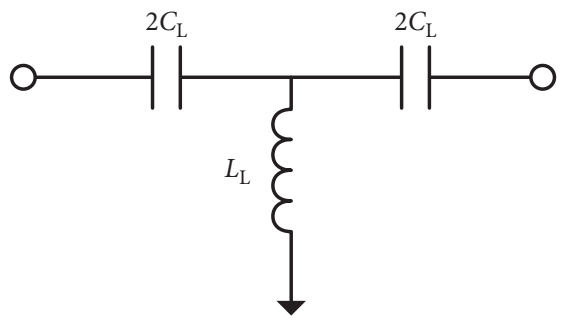

(b)

Figure 1: (a) A section of RHTL and (b) a section of LHTL.

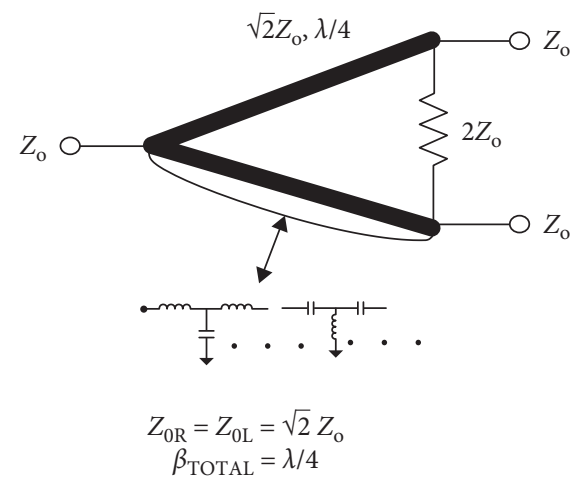

FIGURE 2: Band-selective power divider structure. Quarter-wave length TLs in a conventional Wilkinson power divider are replaced by several sections of an RHTL and an LHTL.

Thus, we can implement a compact, band-selective power divider. When designing the proposed circuit, one should carefully select the values of inductors and capacitors for the desired phase propagation constant, characteristic impedance, and cut-off frequency.

\section{Realization and Measurement}

The band-selective power divider shown in Figure 3 is realized on an FR4 board. The whole circuit is merely $12 \mathrm{~mm}$ by $10 \mathrm{~mm}$ in size. For the RHTL, we used $C_{\mathrm{R}}=7 \mathrm{pF}$ and $L_{\mathrm{R}}=36 \mathrm{nH}$ so that $Z_{0 \mathrm{R}}=71.7 \Omega$ and $f_{\mathrm{Bragg}}^{\mathrm{R}}=634 \mathrm{MHz}$. For the LHTL, we used $C_{\mathrm{L}}=3 \mathrm{pF}$ and $L_{\mathrm{L}}=15 \mathrm{nH}$; therefore, $Z_{0 \mathrm{~L}}=70.7 \Omega$ and $f_{\mathrm{Bragg}}^{\mathrm{L}}=375 \mathrm{MHz}$. We cascaded four sections of RHTL and three sections of LHTL. Using (3), (6), and (7), we calculated that the $90^{\circ}$ phase propagation occurs at $475 \mathrm{MHz}$. We verified that the simulation result is consistent with our calculation.

Figure 4 shows the measured phase balance between output ports (a) and the magnitude response between ports 


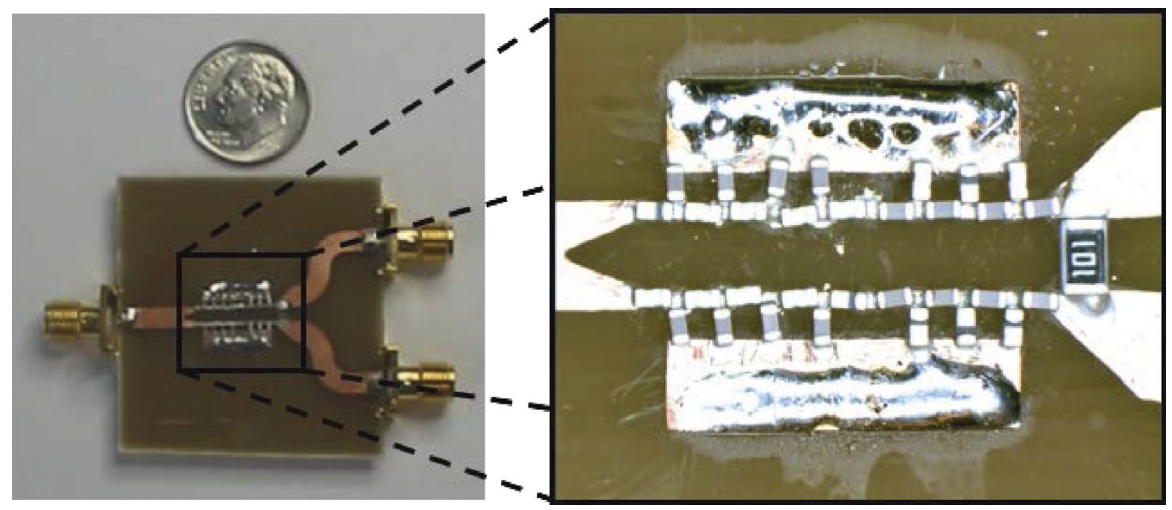

FIgURE 3: Fabricated band-selective power divider. The circuit size is $12 \mathrm{~mm}$ by $10 \mathrm{~mm}$.

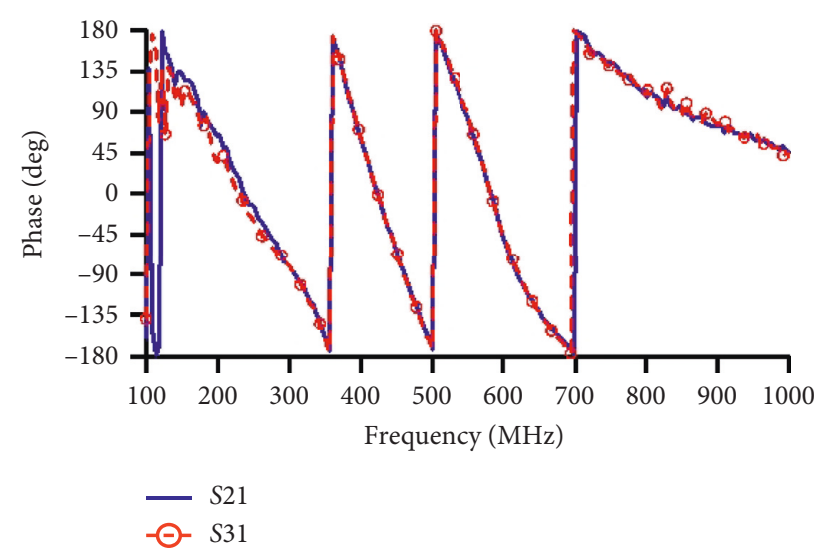

(a)

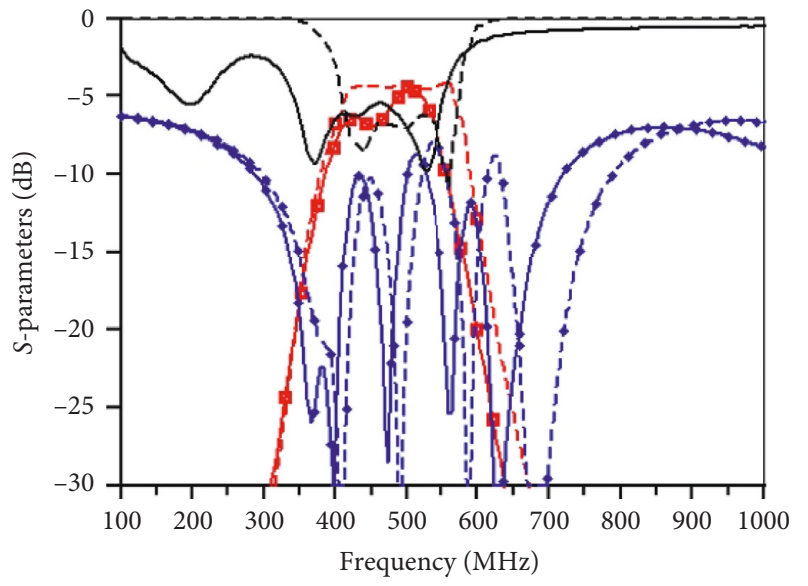

$$
\begin{aligned}
& \text {--- S11 simulated } \quad \text { - S21 measured } \\
& \text { - S11 measured } \\
& \text {-曰- S21 simulated } \\
& \begin{array}{l}
\text { — S23 simulated } \\
\sim \text { \&23 measured }
\end{array}
\end{aligned}
$$

(b)

FIGURE 4: (a) Phase balance between two output ports and (b) measurement and simulated results of a band-selective power divider.

(b) of the proposed circuit. Although the simulated and measured results are consistent with each other, small discrepancies occur owing to nonideal effects such as soldering and imperfect grounding. If the circuit is implemented in an MMIC, such effects are minimized. The phase propagations through the both quarter-wave sections show an almost perfect agreement. The measured insertion loss at the designed frequency $(475 \mathrm{MHz})$ is $2.2 \mathrm{~dB}$. When we consider the passband as $410 \mathrm{MHz}-540 \mathrm{MHz}$, the insertion loss is between $1.7 \mathrm{~dB}$ and $2.5 \mathrm{~dB}$. The insertion loss ripple is merely $\pm 0.4 \mathrm{~dB}$. The average isolation of the proposed circuit within the passband is $-13.5 \mathrm{~dB}$.

\section{Conclusion}

In this paper, we presented a band-selective divider based on the RH, LHTL structure and demonstrated our idea through experimental results. Owing to the RH, LHTL combination structure, we could achieve an effective power dividing with the passband as $410 \mathrm{MHz}-540 \mathrm{MHz}$. A size reduction due to the replacement of $\lambda / 4$ sections of conventional Wilkinson power divider to lumped elements would be more significant when the operational frequency band is lower. This circuit can be effectively applied to various compact microwave systems since it can perform both power dividing and filtering although it occupies an area for only a single circuit.

\section{Data Availability}

The data used to support the findings of this study are available from the corresponding authors upon request.

\section{Conflicts of Interest}

The authors declare that there are no conflicts of interest regarding the publication of this paper.

\section{Acknowledgments}

This research was supported by the Basic Science Research Program through the National Research Foundation of 
Korea (NRF) funded by the Ministry of Education (NRF2019R1F1A1063738).

\section{References}

[1] E. J. Wilkinson, "An N-way hybrid power divider," IEEE Transactions on Microwave Theory and Techniques, vol. 8, no. 1, pp. 116-118, 1960.

[2] D. M. Pozar, Microwave Engineering, Wiley, New York, NY, USA, 3rd edition, 2005.

[3] J. Kim and G. M. Rebeiz, "Miniture four-way and two-way 24 $\mathrm{GHz}$ Wilkinson power dividers in $0.13 \mu \mathrm{m}$ CMOS," IEEE Microwave and Wireless Components Letters, vol. 17, no. 9, pp. 658-670, 2008.

[4] W. Huang, W. Ruan, and F. Tan, "A miniaturized 4:1 unequal Wilkinson power divider using artificial transmission lines and double-sided parallel-strip lines," International Journal of Antennas and Propagation, vol. 2017, Article ID 6751694, 7 pages, 2017.

[5] Y. Sun and A. P. Freundorfer, "Broadband folded Wilkinson power combiner/splitter," EEE Microwave and Wireless Components Letters, vol. 14, no. 6, pp. 295-297, 2004.

[6] C. Q. Li, S. H. Li, and R. G. Bosisio, "CAD/CAE design of an improved wideband Wilkinson power divider," Microwave Journal, vol. 27, pp. 125-135, 1984.

[7] L. Wu, Z. Sun, H. Yilmaz, and M. Berroth, "A dual-frequency Wilkinson power divider," IEEE Transactions on Microwave Theory and Techniques, vol. 54, no. 1, pp. 278-284, 2006.

[8] T. Kawai, Y. Nakashima, Y. Kokubo, and I. Ohta, "Dual-band Wilkinson power dividers using a series RLC circuit," IEICE Transactions on Electronics, vol. E91-C, no. 11, pp. 1793-1797, 2008.

[9] W. Tang, J.-H. Ryu, and H. Kim, "Compact, tunable Wilkinson power divider using tunable synthetic transmission line," Microwave and Optical Technology Letters, vol. 52, no. 6, pp. 1434-1436, 2010.

[10] X. Wang, Z. Ma, T. Xie, M. Ohira, C.-P. Chen, and G. Lu, "Synthesis theory of ultra-wideband bandpass transformer and its Wilkinson power divider application with perfect inband reflection/isolation," IEEE Transactions on Microwave Theory and Techniques, vol. 67, no. 8, pp. 3377-3390, 2019.

[11] W.-M. Chau, W.-H. Tu, and K.-W. Hsu, "Wide-stopband Wilkinson power divider with bandpass response," Electronics Letters, vol. 50, no. 1, pp. 39-40, 2014.

[12] P. K. Singh, S. Basu, and Y.-H. Wang, "Coupled line power divider with compact size and bandpass response," Electronics Letters, vol. 45, no. 17, pp. 892-894, 2009.

[13] O. Hiroshi, C. Christophe, and I. Tatsuo, "A compact enhanced-bandwidth hybrid ring using an artificial lumpedelement left-handed transmission-line section," IEEE Transactions on Microwave Theory and Techniques, vol. 52, no. 3, pp. 798-804, 2004.

[14] H. Kim, S.-J. Ho, M.-K. Choi, A. B. Kozyrev, and D. W. van der Weide, "Combined left- and right-handed tunable transmission lines with tunable passband and $0^{\circ}$ phase shift," IEEE Transactions on Microwave Theory and Techniques, vol. 54, no. 12, pp. 4178-4184, 2006.

[15] H. Kim, A. B. Kozyrev, A. Karbassi, and D. W. van der Weide, "Linear tunable phase shifter using a left-handed transmission line," IEEE Microwave and Wireless Components Letters, vol. 15, no. 5, 2005. 


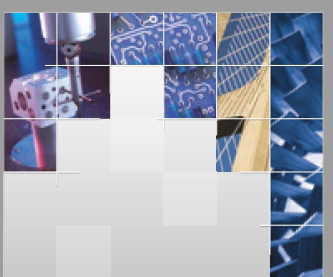

\section{Enfincering}
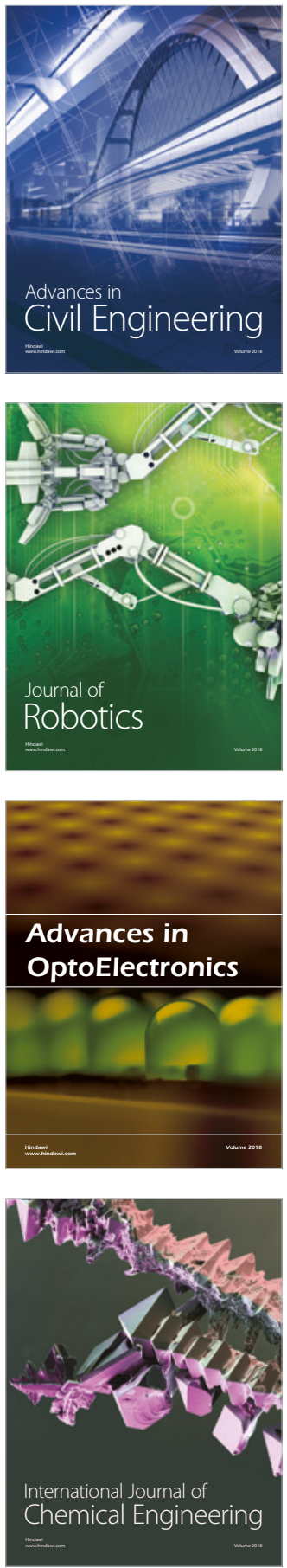

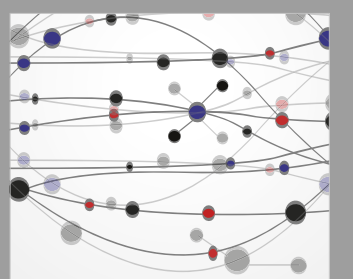

\section{Rotating \\ Machinery}

The Scientific World Journal

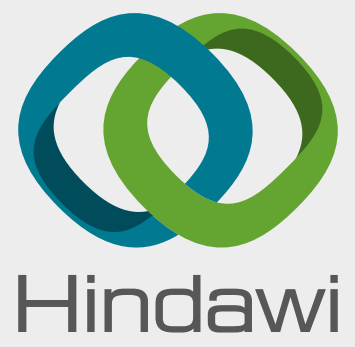

Submit your manuscripts at

www.hindawi.com
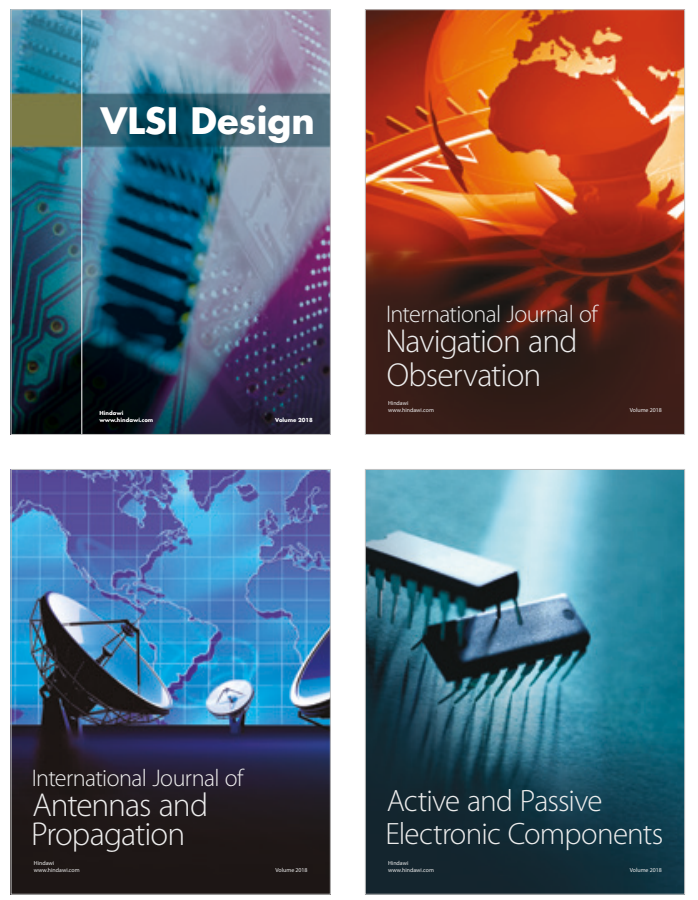
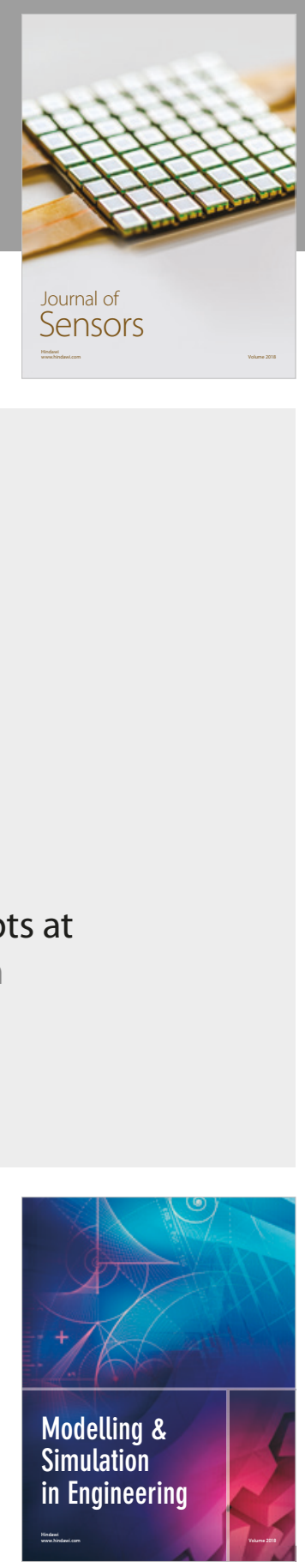

\section{Advances \\ Multimedia}
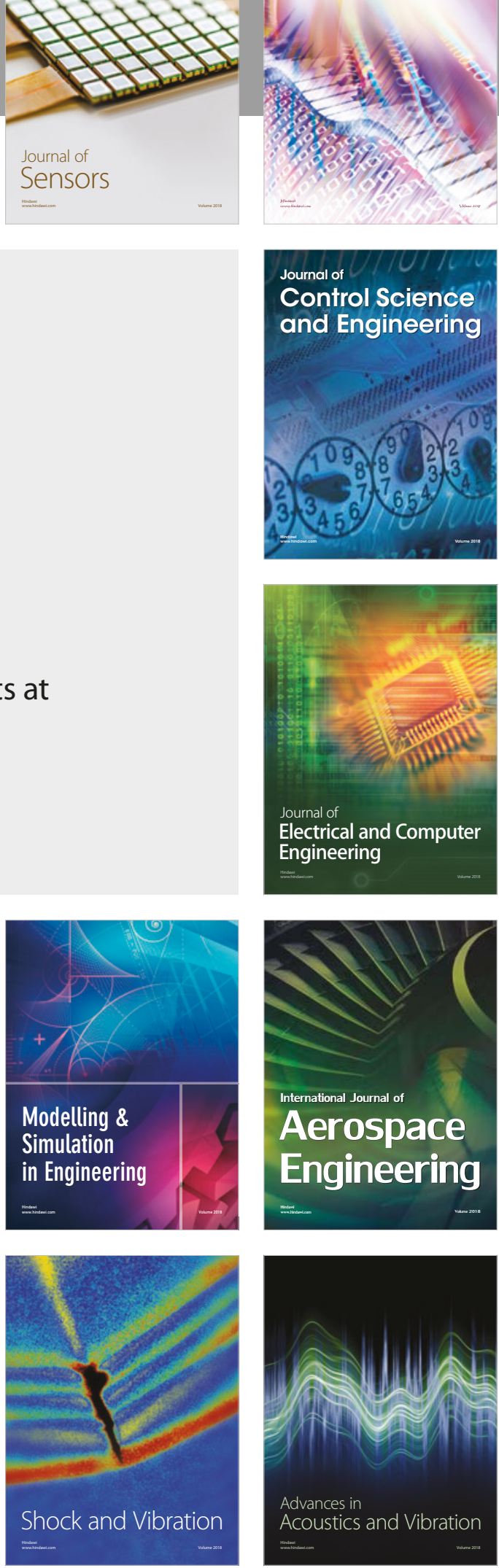